\title{
Oral metastasis from rectal adenocarcinoma: case report
}

\author{
Alhadi Almangush ${ }^{1}$, Antti Asikainen ${ }^{2}$, Ari Ristimäki ${ }^{3}$, Caj Haglund ${ }^{4}$, Jaana Hagström ${ }^{5}$ \\ 1. Department of Pathology, Haartman Institute, University of Helsinki, Helsinki, Finland; and Institute of Dentistry, \\ University of Misrata, Misrata, Libya. 2. Department of Oral and Maxillofacial Surgery, Helsinki University Central Hospital, \\ Helsinki, Finland. 3. Department of Pathology, Haartman Institute and Huslab, Helsinki University Central Hospital, \\ Helsinki, Finland. 4. Department of Surgery, Helsinki University Central Hospital and Research Programs Unit, \\ Translational Cancer Biology, University of Helsinki, Helsinki, Finland. 5. Department of Pathology, Haartman Institute and \\ HusLab; and Department of Oral Pathology, Institute of Dentistry, University of Helsinki, Helsinki, Finland.
}

Correspondence: Jaana Hagström. Address: Department of Pathology, Haartman Institute, P.O.Box 21, FIN-00014 University of Helsinki, Helsinki, Finland. E-mail: jaana.hagstrom@hus.fi

Received: January 21, $2014 \quad$ Accepted: April 14, $2014 \quad$ Online Published: April 29, 2014

DOI : $10.5430 /$ crcp.v1n2p63 URL: http://dx.doi.org/10.5430/crcp.v1n2p63

\section{Abstract}

For oral metastases, the most common primary sites are lung and prostate among male patients and breast among females, but oral metastasis from rectal adenocarcinoma is extremely uncommon in both genders. Tumors tend to metastasize to jaw bones more often than to oral soft tissues. In case of oral soft tissue metastases, the gingiva and the tongue are the most commonly involved sites. The prognosis of patients with oral metastases is poor; but early detection and effective treatment are necessary to avoid patient discomfort, secondary infection and subsequent tissue destruction.

Here we report a case of rectal adenocarcinoma that metastasized to the oral mucosa of the lower buccal sulcus. Pain and discomfort during chewing were the main complaints. In this case report, the histopathological findings, the management of the oral metastasis, and patient prognosis are discussed.

\section{Key words}

Oral metastases, Rectal adenocarcinoma, Prognosis

\section{I ntroduction}

Metastasis is a complex process and considered as the most fatal step during the cancer progression. However, metastasis to oral region is uncommon and usually associated with poor prognosis. Metastatic tumors comprise only $1 \%$ of oral cancer cases ${ }^{[1]}$. The diagnosis of oral metastasis is challenging and should be considered in the differential diagnosis of oral inflammatory lesions ${ }^{[2]}$. We report a case of rectal adenocarcinoma which developed metastasis to the oral mucosa of the lower buccal sulcus.

\section{Case report}

In April 2011, a 61-year-old woman had undergone transanal excision of $2.5 \mathrm{~cm}$ (pT2) poorly differentiated adenocarcinoma of the distal rectum. At the time of diagnosis she had multiple liver metastases, but no other metastases at 
CT scan. Postoperatively, she was treated with chemotherapy, XELOX (cabecitabine and oxiplatin) plus bevacizumab between May 2011 and February 2012. After a period of response, chemotherapy regimens was changed to FOLFIRI (irinotecan plus fluorouracil and folinic acid) plus ramucirumal between March and July 2012, and further to cabecitabine plus mitomycin C between August and September 2012. Thereafter, chemotherapy was terminated because of progression of the disease. She was diagnosed with metastases in spine and skin, in addition to the oral metastasis described below.

In July 2012 she got discomfort from a red mass about $3 \mathrm{~cm}$ in diameter located posteriorly in the mucosa of the lower buccal sulcus of the right side (see Figure 1). No other oral lesions were seen. She complained that the mass emerged between her teeth during chewing and caused pain. This oral mass was resectable, therefore, in September 2012 it was removed to reduce discomfort while chewing. After excision, she received palliative radiotherapy 9 times $3 \mathrm{GY}$, but the clinical course of the patient was very aggressive, and she died in October 2012.

Figure 1. The oral lesion in the right side of lower buccal sulcus

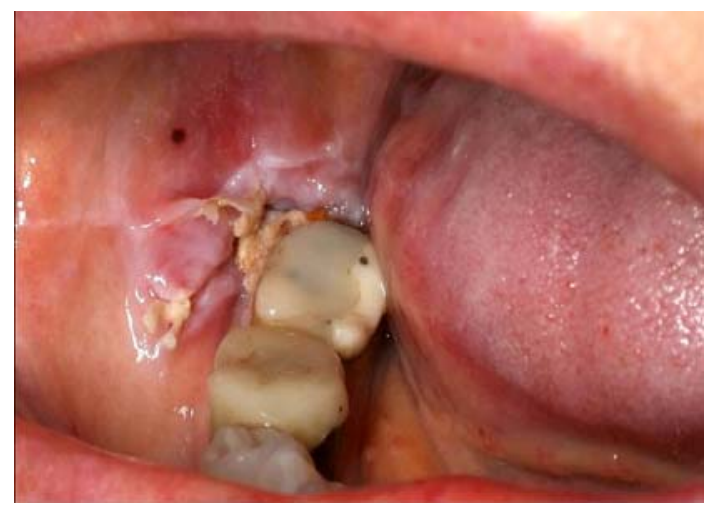

At histology, under the ulceration area, poorly differentiated carcinoma tissue was seen invading into muscle and fat tissue. Mitoses were easily detectable and the tumor grew in island like pattern without connection to top epithelium. Because the patient had a history of rectal adenocarcinoma, diagnosis was verified by immunohistochemistry to evaluate the possibility of rectal adenocarcinoma metastasis. At the histopathological re-examination of the archive slides of the rectal carcinoma, morphological similarity of the oral tumor with the removed rectal adenocarcinoma was shown (see Figure 2).
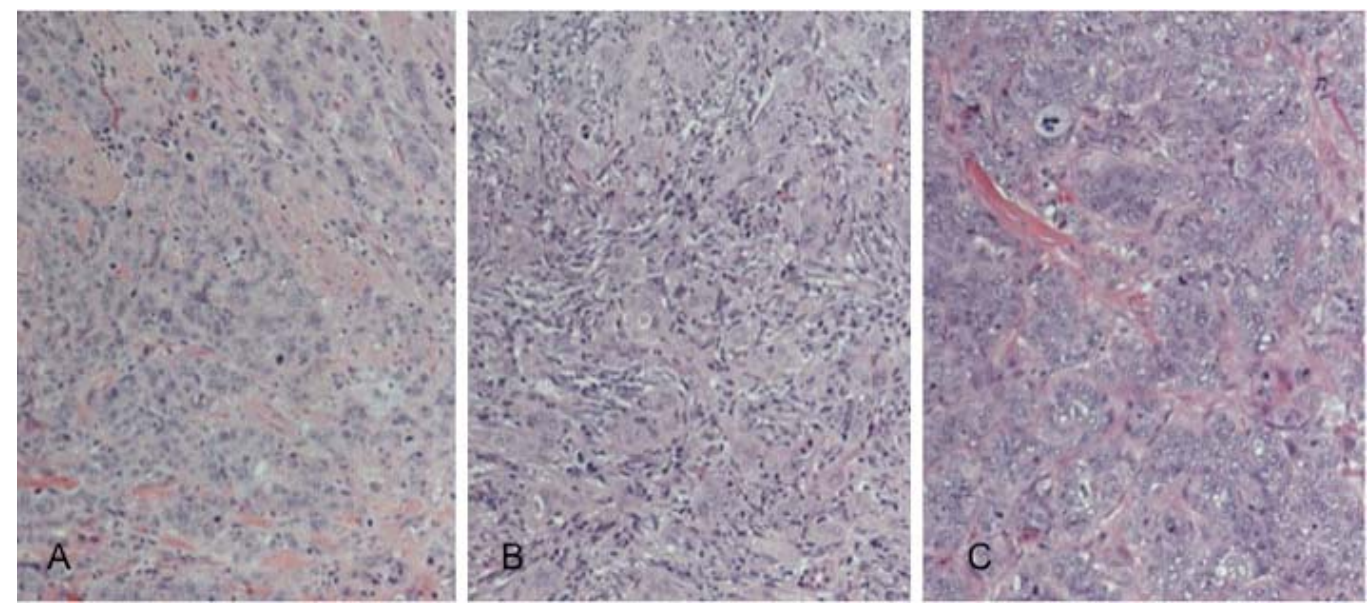

Figure 2. A: Primary in rectum; B: liver metastases; C: Oral metastases. HE staining. $\times 200$

The oral tumor was positive for cytokeratin CKpan, CK 7, CK 19, and some positivity was seen for CK20, CK5/6, p63 and CEA (see Figure 3). The tumor was negative for CA19.9, CDX2, CD10, (TTF-1), and estrogen. The primary rectal tumor diagnosed earlier had the same immunoprofile as the oral lesion. However, during the diagnosis of the colon cancer it was discussed whether it could be transitional cancer or adenocarcinoma originating from anal glands because this immunoprofile was not the typical for colon cancer. 
Figure 3. A-D: Rectal primary; E-H: Oral metastases. Immunoprofile of the rectal tumor and metastases to oral cavity.

(A and E: Ck20) (B and F: CK7) (C and G: CDX2) (D and H: CA19_9)

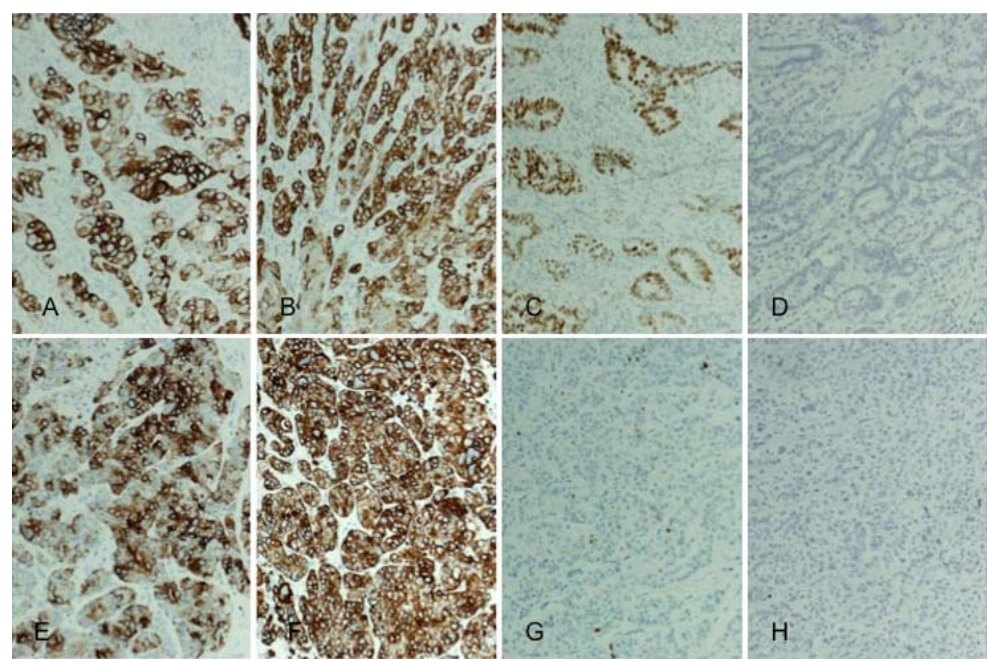

\section{Discussion}

The prognosis of advanced stage rectal cancer is poor and associated with risk of local recurrence and of distant metastases ${ }^{[3]}$. Metastases of rectal adenocarcinoma to the oral cavity are rarely reported. Usually, pain is one of the main symptom of oral metastases ${ }^{[4]}$, in addition, swelling, bleeding, and paresthesia may be present.

Patients with malignant tumors metastasizing to the oral cavity have usually poor prognosis, since oral metastases usually indicate widely disseminated disease. In this case, in addition to the oral metastasis, the patient had a liver, bone and skin metastasis. The liver metastasis was discovered at CT scan two weeks before the rectal operation. The liver metastases identified by a core biopsy did not respond to palliative chemotherapy.

The treatment of choice for limited oral metastases is surgical resection. In the case reported here, local surgical resection of the oral lesion was performed, and after resection the patient received palliative radiotherapy. Also in cases with widely disseminated oral metastases where surgical resection is impossible, palliative therapy is recommended to reduce symptoms. Often, despite this treatment strategy, survival after the diagnosis of oral metastases in these advanced cases is around six months ${ }^{[5]}$.

In this case, histopathological features and immunohistochemical staining similarity to the original rectal tumor and liver metastases provided the information to conclude that the primary tumor was the rectal adenocarcinoma diagnosed in 2011.

However, the possible primary tumor is not always known beforehand. Accurate pathological examination with various immunohistochemical staining is often important to define the site of primary lesion. Immunostaining CK 20 is not positive in oral cancer, so when positive in oral lesion it suggests metastatic origin mainly from intestinal area. In our case, the primary colonic tumor had not typical colon cancer immunoprofile (CK 7 + and CDX2 -).

Metastases directly to the oral mucosa are uncommon. Usually, oral mucosal metastases are extensions from jaw bone metastases, spreading beyond the periosteum and causing visible oral mucosal lesion ${ }^{[6]}$. In our case, no jaw-bone involvement was present and the oral metastatic lesion was restricted to the soft tissues of the involved area.

Metastatic tumors comprise only $1 \%$ of oral cancer cases ${ }^{[1]}$, and they mainly associated with patient outcome ${ }^{[7]}$. Metastases usually involve the gingiva ${ }^{[8]}$, and the clinical appearance may present as a pyogenic granuloma or epulis ${ }^{[9]}$. Therefore, misdiagnosis of oral lesions by family dentist has been reported ${ }^{[10]}$. In our case, the tumor rather mimicked an oral ulceration or squamous cell carcinoma. 
In conclusion, this case report highlights the importance of prompt biopsy, appropriate consultation and thorough examination of the disease history of patients with oral mucosal lesions. Thorough follow-up of any oral lesions is important, especially if the lesion presents any malignant features or when the patient has a history of previous malignancy. In order to make a proper diagnosis, close collaboration between clinician and pathologist is advocated.

\section{Conflict of interests}

The authors declare that they have no conflict of interests.

\section{References}

[1] D'Silva NJ, Summerlin DJ, Cordell KG, et al. Metastatic tumors in the jaws: a retrospective study of 114 cases. J Am Dent Assoc. 2006; 137: 1667-72. PMid: 17138711. http://dx.doi.org/10.14219/jada.archive.2006.0112

[2] Hirshberg A, Shnaiderman-Shapiro A, Kaplan I, Berger R. Metastatic tumours to the oral cavity - pathogenesis and analysis of 673 cases. Oral oncol. 2008; 44: 743-52. PMid: 18061527. http://dx.doi.org/10.1016/j.oraloncology.2007.09.012

[3] Sauer R, Becker H, Hohenberger W, et al. Preoperative versus postoperative chemoradiotherapy for rectal cancer. N Engl J Med. 2004; 351: 1731-40. PMid: 15496622. http://dx.doi.org/10.1056/NEJMoa040694

[4] Pruckmayer M, Glaser C, Marosi C, Leitha T. Mandibular pain as the leading clinical symptom for metastatic disease: nine cases and review of the literature. Ann Oncol. 1998; 9: 559-64. PMid: 9653498. http://dx.doi.org/10.1023/A:1008286117771

[5] Van der Waal RI, Buter J, van der Waal I. Oral metastases: report of 24 cases. Br J Oral Maxillofac Surg. 2003; 41 : 3-6. http://dx.doi.org/10.1016/S0266-4356(02)00301-7

[6] Rentschler RE, Thrasher TV. Gingival and mandibular metastases from rectal adenocarcinoma: case report and 20 year review of the english literature. Laryngoscope. 1982; 92: 795-7. http://dx.doi.org/10.1288/00005537-198207000-00015

[7] Seoane J, Van der Waal I, Van der Waal RI, et al. Metastatic tumours to the oral cavity: a survival study with a special focus on gingival metastases. J ClinPeriodontol. 2009; 36: 488-92. PMid: 19508248. http://dx.doi.org/10.1111/j.1600-051X.2009.01407.x

[8] Sanchez-Jimenez J, Acebal-Blanco F, Arevalo-Arevalo RE, Molina-Martinez M. Metastatic tumours in upper maxillary bone of esophageal adenocarcinoma. A case report. Med Oral Patol Oral Cir Bucal. 2005; 10: 252-7. PMid: 15876970.

[9] Moffat DA. Metastatic adenocarcinoma of the rectum presenting as an epulis: a case report. Br J Oral Surg. 1976; 14: 90-2. http://dx.doi.org/10.1016/0007-117X(76)90100-1

[10] Kawamura M, Nakabayashi Y, Otsuka M, Sakata H, Yanaga K. Gingival metastasis from rectal cancer. J Gastrointest Surg. 2008; 12: 1121-2. PMid: 18000717. http://dx.doi.org/10.1007/s11605-007-0401-y 